\title{
LA SITUACIÓN SOCIAL DE LAS ESCRITORAS ARGENTINAS EN LAS PRIMERAS DÉCADAS DEL SIGLO XX. ANTECEDENTES
}

\author{
Ricardo Szmetan*
}

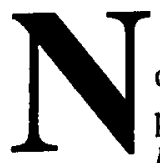

o se necesita ser un convencido marxista para estar de acuerdo con la premisa de Karl Marx, en el prefacio a la Contribución a la crítica de la política económica (1976), en cuanto a que no es la conciencia del hombre la que establece o dirige su existencia, sino que, por el contrario, es su existencia como parte de la sociedad la que influye en la formación de su conciencia. Pese a esta concepción un tanto determinista de la historia, habiendo trabajado en el tema de la situación social del escritor en la Argentina de las primeras décadas del siglo $\mathrm{XX},{ }^{1}$ aun así me llamó la atención lo poco que se puede mencionar a las mujeres en su calidad de escritoras, aunque las hubiera por cierto y tuvieran una nada desdeñable actuación dentro de la misma.

Es sabido que la sociedad en Latinoamérica tiene, en general, rígidos roles jerárquicos y un discurso no menos definido en cuanto a los límites que se impone a cada grupo. Por cierto que la Argentina no escapaba a este orden de cosas, siendo que la mujer allí tiene limitaciones consideradas por muchos como normales, tanta es la fuerza de la tradición e ideología dominante. Desde la perspectiva de una crítica feminista consciente de esta situación, al origen de mucha de esta sombría realidad se encuentra un discurso de índole patriarcal

* Arizona State University 
SZMETAN R. La situación social de las escritoras argentinas...

sostenido por representantes de los grupos sociales más aventajados. Existe así una artificial división entre hombres y mujeres, y en particular entre lo considerado como femenino y masculino, y se da por sobreentendida la supuesta superioridad del hombre por su mayor fuerza física y, tautológicamente, por ocupar los principales puestos de conducción en la sociedad. Además, siguen siendo preponderantes antiguas costumbres sobre el rol que cada uno debería tener dentro del núcleo familiar, más que las consideraciones a las reales diferencias biológicas. De esta manera se buscaría perpetuar la prioridad del hombre por sobre la mujer.

Aunque el tema es amplio y bastante complicado, ha sido bien estudiado entre otras por Kate Millett (1969), Jane Gallop (1982), Héléne Cixous (1991) y la decana de los estudios feministas, Simone de Beauvoir $(1949,1970)$ quien, comentando sobre la situación de aparente sumisión de la mujer ante las fijas reglas de la sociedad, afirmaba que: "One is not born a woman, one becomes one" (p. 301). Es decir, que en la formación del rol que se supondría debería jugar la mujer como individuo, hay muchos estereotipos condicionantes y, peor aún, se la define y diferencia en relación al hombre y no - como debería ser en referencia a ella misma, lo que hace que, en muchos aspectos, él sea considerado el Sujeto y ella la Otra suya. Esta visión de alteridad es remarcada por los modelos más tenidos en cuenta, que casi siempre son los masculinos, aunque esté cambiando la situación con el paso del tiempo y la cada vez menor fuerza imperante de muchas de las tradiciones en boga.

Con las mujeres escritoras argentinas de principios de siglo estaba además el crucial interrogante de saber si podían vivir de manera directa o indirecta de lo que les diera la escritura, si no como creadoras - ya que muy pocos de todas maneras lo conseguían, aun los de sexo masculino que tenían mayor éxito - , por lo menos que el relativo reconocimiento popular las ayudara a conseguir trabajo para dedicarse con más facilidad a las actividades artísticas e intelectuales. Pese a la voluntad en contrario, tampoco es mucho ni muy favorable lo que se puede decir al respecto. Además, el tema no siempre ha tenido la importancia que merece en el ámbito latinoamericano, y no existen todavía en el mismo estudios como, por ejemplo, los de Sandra Gilbert y Susan Gubar con su The madwoman in the Attic (1984), sobre las restricciones culturales que sufrían las escritoras retratadas en las literaturas británica y estadounidense del siglo XIX, y cómo aún así trataban de tener una unidad temática que mostrara - bien que solapadamente - la situación en que se encontraban y su latente rebelión.

Ciertamente, la gran mayoría de las pocas mujeres que escribían eran de familias acomodadas, mientras que las demás debían trabajar para poder vivir o 
seguir con la minoritaria práctica tradicional de tomar los hábitos, o casarse - si querían o podían - , casi como una suerte de imposición social, más en el interior del país que en la cosmopolita Buenos Aires. Les quedaba el trabajo en el magisterio - por entonces bien pago - , mientras que estudiar en la universidad - no hablemos de ser profesora en ella - era en verdad una rareza. Tal vez se las viera en la Facultad de Letras o en las Academias de Bellas Artes o de Música, casi nunca en las demás instituciones culturales y educativas.

En un ambiente dispuesto de esta manera, la ideología imperante se encargaba de que cada una de ellas tuviera una relación imaginaria con la realidad circundante, no siendo responsables como centros de iniciativa para tratar de modificar la identidad creada por la sociedad y a la cual llegaban con una herencia determinada. Además, había toda clase de impedimentos y cra muy difícil poder eludirlos. Como bien lo nota Hayden White: "Like desire and power, discourse unfolds in every society within the context of external restrains that appear as rules of exclusion, rules that determinates what can be said or not said, who has the right to speak on a given subject (...) what will count as true and what as false" (p. 112). Por eso, no debe llamar demasiado la atención que las mujeres tampoco formaran parte de la dirigencia de las organizaciones culturales; y si a veces participaban en las reuniones de los cenáculos de escritores, era más a título decorativo que otra cosa, salvo en el caso particular de Alfonsina Storni (1892-1938), la primera mujer en frecuentar activamente esas reuniones, como ya lo indicara Roberto F. Giusti (Roxlo-Mármol, p. 64). A partir de ella y principalmente a partir de finales de la década del treinta, empezarán a aparecer cada vez más otras escritoras que compartirán la vida pública con sus congéneres varones, pero siempre en menor medida a lo que se podría esperar. De ellas se recuerda principalmente a las hermanas Ocampo: Silvina (1903-?), y muy particularmente Victoria (1890-1970), quien tuviera bajo su égida un grupo muy destacado de artistas y una de las revistas de mayor predicamento y larga vida: Sur (1931-1970). ${ }^{2}$

Se puede citar también casos anteriores de escritoras de familias pudientes que vieron sus obras publicadas, casi siempre costeadas de su propio bolsillo, como las que se hacían editar en París, no sólo porque era más distinguido, sino también - en muchos casos - más barato. Estaba por ejemplo la prolífica educadora y periodista Juana Manso de Noronha (1820-75) que escribiera Lo.s misterios del Plata (1846), que sólo saldría publicada mucho más tarde, en 1899. con algunas páginas preparadas por otro autor, ya que para entonces seguía estando incompleta. La novela es muy crítica - como la gran mayoría de las escritas sobre el tema en la época, y después - del gobernador de Buenos Aires, Juan M. de Rosas (1793-1877), lo que le valió a ella, y a su familia, el 
SZMETAN R. La situación social de las escritoras argentinas...

acostumbrado - por entonces - exilio. La propia autora afirmaba haberla publicado con el seudónimo Avellaneda, pero no se encuentran rastros de esa edición. Está ambientada en el Brasil donde viviera de muy joven durante su destierro, lo mismo que La familia del comendador (1854), que primero apareció como folletín, como la gran mayoría de las obras que se conocen de por entonces. Además publica Un compendio de historia de las Provincias Unidas del Río de la Plata (1862), que fue muy popular como texto escolar por muchos años.

Por su parte, Juana M. Gorriti (1818-92) era la hija del famoso militar norteño José I. Gorriti, participante de las gestas de independencia. Es la creadora, según Myron Lichtblau (p. 29-30), de la considerada como primera novela corta de autor argentino: La quena, pese a que su trama transcurre en Perú, donde se exilara con su familia y no se hace referencia a temas argentinos. Primero apareció en capítulos en La Revista de Lima, en 1845, y en forma de libro en 1865 en Buenos Aires. Entre sus muchas obras se pueden citar también Sueños y realidades (1865) y Panoramas de la vida (1876). Eduarda Mansilla de García (1835-92), es otra escritora que procedía de una familia tradicional, ya que era hija del general Lucio Mansilla y de Agustina Rosas, hermana del gobernador J. M. de Rosas, mientras que su hermano era el conocido escritor y militar Lucio V. Mansilla (1831-1913). Ella publica Lucía en La Tribuna, bajo el seudónimo de Daniel, entre el 10 de mayo al 4 de julio de 1860 . Mucho después, en 1882 y bajo su nombre verdadero, aparece esta obra sin cambios pero esta vez con el título de Lucía Miranda. El romantizado tema de la novela forma parte de la tradición histórica que llega hasta los tiempos de la Independencia, y es el amor de Lucía por el jefe indio Mangora y el asesinato de ambos por Siripo. Curiosamente, la que mejor trataría el tópico sería Rosa Guerra $(i-1894)$, de la que apenas se conocen datos de su vida y quien publicara un libro con el mismo título en 1860 . Entre sus demás novelas también se destaca El médico de San Luis (1860).

Estos ejemplos son de escritoras que se darían a conocer en el inicio del siglo XX, con el mayor desarrollo de las instituciones culturales del país, fruto en parte del plan desarrollado por los miembros de la Generación del 80 . Aun así, las nombradas son casi las únicas que se pueden citar, y no pasan de ser excepciones a la regla general de (auto) excluimiento que se nota con ellas. Aparte, sus obras nunca tuvieron mayor difusión, más allá de que eran bastantes modestas en sus cualidades intrínsecas. Michael Foucault es de los que mejor entiende los vericuetos del al parecer homogéneo Poder, que casi siempre está diseminado y sujeto a sus propias contradicciones internas, ya que sólo expresa una parte de la realidad. Además, para mantenerse debe fomentar estereotipados roles que, en este caso, se esperaba tuviera la mujer. También hace notar el 
SZMETAN R. La situación social de las escritoras argentinas...

peligro que conlleva para el orden constituido el discurso de los considerados como diferentes, al revelar que: "in the free play of words, the arbitrariness of every rule and norm, even those on which society itself, with its rules of exclusion and hierarchical order, is founded" (White, p. 113). Y pide evitar que sólo el monológico discurso en boga sea el escuchado, liberándolo de cualquier impedimento formal impuesto por el hábito, para abrirlo una vez más "to the Sadean proyect of saying everything that can be said in as many ways as it can be said" (White, p. 113), y cerrar, dentro de lo posible, la distancia que hay entre las palabras y las cosas que bien o mal representan. Esto era todo lo contrario de lo que pasaba en la Argentina de principios de siglo, donde convenía que las mujeres no tuvieran voz propia sino a través de la visión masculina, tanto a nivel político, social como literario.

Quien se fije en los principales nombres de escritoras $-y$ aun en los secundarios -, podrá apreciar como en territorio argentino, mismo desde su comienzo como colonia española y hasta bien entrado el siglo $\mathrm{XX}$, los ejemplos a nombrar son bien pocos. Como el aspecto social y económico del artista en general nunca fue fácil en ninguna parte, más allá del prácticamente desaparecido mecenazgo, no es de extrañar que tampoco lo fuera allí, aunque los escritores varones contaban ciertamente con más posibilidades prácticas que sus colegas mujeres. Piénsese en la difícil situación de un escritor que no tuviese mayores bienes heredados $y$ - en menor medida - de un nombre de familia patricio, ya que estaría obligado a usar de su pluma para subsistir. Muy diferente sería el caso si fuese rico y de buena cuna como el citado L. V. Mansilla, por ejemplo, creador de obras costumbristas sin gran relieve salvo Una excursión a los indios Ranqueles (1870), en donde, desde la posición de un militar victorioso aunque respetuoso de las tradiciones de los vencidos, muestra una realidad que marcó a toda América durante siglos y es tal vez su característica principal: el sometimiento a la fuerza de los indios, cuya consecuencia no sólo fue su matanza sistemática con pocos parangones en la historia universal, sino también la creación de grandes latifundios y la preservación de una casta de familias que dominarán casi todos los estamentos sociales y fijarán hegemónicamente la ideología en vigencia.

Otro ejemplo de escritor de élite era Eugenio Cambaceres (1843-88), creador de novelas naturalistas poco recordables salvo Sin rumbo (1885), precursora del decadentismo en Latinoamérica. También se debe mencionar a Gregorio de Laferrère (1867-1913), exitoso autor de obras teatrales costumbristas propensas a la risa fácil como ;Jettatore! (1904), Locos de verano (1905) o Las de Barranco (1908), que tenía un argumento más profundo, con el afán de una madre de familia de nombre - pero venida a menos - por casar bien a sus 
SZMETAN R. La situación social de las escritoras argentinas...

hijas a cualquier precio, mostrando como su propia clase estaba perdiendo los privilegios de sangre y posesión de la tierra, en detrimento del avance-sin pausa ni tregua - de un capitalismo cada vez más exitoso, pero poco respetuoso de las costumbres del país. Estos escritores - y algunos otros - mostraban a veces una actitud un tanto xenófoba ante el aluvión de extranjeros provenientes de la empobrecida Europa, que hacía que en un tiempo llegaran hasta ser más numerosos que los propios nativos.

Con estos ejemplos se podría pensar en diletantes, causadores, que escribían para divertirse y matar un poco el ocio de todos los días. Con menos nombre y bienes, aunque con los contactos necesarios, estaba Manuel Gálvez (1882-1962), un novelista realista que obtenía bastante éxito de ventas y crítica. Sus obras más destacables son El mal metafísico (1914), en donde muestra vivamente la vida de bohemia de su juventud, y La maestra normal (1916), en la que expone los perjuicios provincianos hacia una maestra que, seducida, decide tener un hijo natural. Por su parte, Nacha Regules (1919) trata de los estragos sociales que produce la prostitución y, finalmente, se destaca Hombres en soledad (1938) que, como el mismo título lo indica, es el testimonio de la soledad del artista pocas veces comprendido, no sólo por la sociedad en su conjunto, sino también por sus propios colegas, muchas veces indiferentes y hasta envidiosos de la vida y obra ajenas. A otro nivel, se puede citar también a Hugo Wast (seudónimo de Gustavo Adolfo Martínez Zuviría 1883-1961) y su gran éxito popular con novelas chirles, fácilmente olvidables, tales como Alegre (1906), Flor de durazno (1911), Valle negro (1918), y muchas otras con ingredientes romantizados prestados de las novelas de cordel europeas, con predecibles personajes y argumento por lo demás maniqueo.

Si de todas maneras a ellos la clase alta los tenían como propios, igual los consideraban unas suerte de ovejas negras, bohemios trasnochadores, soñadores poco prácticos que vivían en un mundo aparte, aunque en realidad muchos tuvieran que trabajar como periodistas o escribir piezas de teatro para el lucimiento de los capocómicos de moda que, junto con los empresarios, eran los reales beneficiados económicamente de esta situación. Los más debían contentarse con llegar malamente a fin de mes; esto en un país que hasta por lo menos 1937 estaba entre los diez primeros del mundo en cuanto al nivel de vida de sus habitantes.

Con la creación de importantes instituciones culturales ${ }^{3}$ y de la primera cátedra de literatura argentina en la Facultad de Letras de la Universidad de Buenos Aires, en 1921, que recayera en el incansable y pragmático Ricardo Rojas (1784-1824), ejemplo del sistema de crítica patriarcal, se nota un creciente interés por la literatura nacional. Ayuda también la aparición de revistas de 
calidad como Nosotros (1907-34; 1936-43), y de bastantes nuevos escritores y críticos que publican a menudo en diarios y revistas de actualidad de creciente tiraje, pero aún así son muy pocas las mujeres que se pueden citar. ${ }^{4}$ Muchos surtían novedades a un - al parecer - nunca satisfecho mercado de lectores, cada vez más amplio pero al mismo tiempo poco sofisticado. El mismo auge y características se notaba asi-mismo en la abundante edificación de teatros, donde a veces se estrenaban a diario piezas rápidamente escritas y más pronto olvidadas. Así, en este propicio ambiente la un tanto indirecta profesionalización del escritor es un hecho, pese a que casi no quedaran mecenas y no fuera como antes en que el escritor - jamás la escritora - era también un personaje político, ocupando los cargos de gobierno más importantes.

En esta sociedad cada vez más mercantilizada se hacía sentir la nueva división del trabajo, y el escritor, en su mayoría de clase media con nombre de familia que hacía ver su origen foráneo, debió acostumbrarse al escaso reconocimiento social. Entre tanto, ¿qué pensar de la mujer escritora? A lo más, algunas se atrevían tímidamente a ser poetas. Sino, caso contrario, habría que recordar que mismo la novela Stella (1905), uno de los primeros grandes éxitos de ventas de principios de siglo, fue escrita bajo el seudónimo de César Duayen, ya que su autora, Emma de la Barra de Llanos (1861-1947), temía las repercuciones que la misma podría tener entre la buena sociedad. Recién en 1933 reconoce en un reportaje dado a la revista El Hogar y en parte transcripto por María G. Mizraje (1997), que: “¿Cómo iba a atreverme a firmar una novela? ¡Qué esperanza! Era exonerarme al ridículo y al comentario."

Como queda dicho, algunas atrevidas se permitían ir a las reuniones de los círculos literarios, más no fuera que para poner una nota pintoresca en los mismos, pero en las instituciones culturales no era casi cuestión de que pudieran participar. Les quedaba el entonces bien pago trabajo del magisterio, pero que quitaba mucho tiempo para la obra creativa. No era tampoco común que trabajasen en el periodismo, lo que a lo menos las hubiera ayudado en la difícil práctica de la escritura, aunque muchas veces fuera sobre temas de momento y no los que cimentan la trayectoria de un escritor; si bien de esta manera podían ganar un magro salario que, por otra parte, no siempre se pagaba.

Interesante es destacar como en el cuidadoso y completo trabajo de Augusto González Castro (1966) sobre las historias y antologías de la literatura argentina, la primera alusión a una mujer es como destinataria de la poesía y no como creadora de la misma: Album poético para niñas (1902), preparado por J. B. Igón. La posible primera mención de una escritora es recién en 1917 en la Antologia de poetas jóvenes (Galíndez) en donde, entre cuatro escritoras que no aparecen después en otras compilaciones, se hace alusión a Storni, cuyo nombre 
SZMETAN R. La situación social de las escritoras argentinas...

a través de los años será el más mencionado de entre todas las mujeres. En ese mismo año, en la antología preparada por Ernesto Morales y Daniel Novillo Quiroga, aparece el nombre de la prolífica esposa de M. Gálvez, Delfina Bunge de Gálvez (1881-1952), entre los cuatro escritores mencionados. Curiosamente, en el rubro de autores argentinos de su Lectura para mujeres (1924), la laureada Mistral elige sólo a dos escritores: Leopoldo Lugones (1878-1938) y Arturo Capdevilla (1889-1967), ambos varones. El compendio de María Monvel (1930), por su parte, es bastante curioso, ya que eligiendo entre los trabajos de las poetisas, se pregunta el porqué hay tantas, llegando a la siguiente insólita conclusión: ¿Se tra-taría acaso de la liberalidad en las costumbres y del respeto con que se escucha entre nosotros el perpetuo vagido amoroso de las mujeres? Seguramente es esta la razón y no otra cualquiera" (González Castro, p. 183-84).

\section{Alfonsina Storni}

Su caso es una excepción a la regla general de exclusión de las mujeresescritoras ya mencionadas, y además por su importancia como poeta y su éxito popular, merece un párrafo especial, ya que su significación para las letras argentinas ya resulta evidente. ${ }^{5}$ Es autora de finos poemarios tales como Irremediablemente (1919) en donde, en un lenguaje aparentemente simple, expresaba las emociones más profundas del alma femenina ante el amor no correspondido y la angustia del tiempo que pasa inexorablemente sin que nada al parecer cambie. Pocas tuvieran su talento y popularidad, sin duda no menores a los de Gabriela Mistral (1889-1957), a la que algún sueco de la Academia se había tomado el trabajo de traducir y así abrirle la puerta al justamente - ya para la época - cuestionado, pero consagrador para el establishment y principescamente remunerado, premio Nobel.

No sólo Storni era mujer, y además una de origen humilde, sino que también, ciertamente, no de las más agraciadas físicamente como para hacerle ganar favores o respaldo inmediatos, por lo que no tuvo en vida el reconocimiento que merecía. Eso sí, entre sus congéneres fue de las primeras que intentó ganarse la vida como escritora o que al menos que su bien conquistado prestigio y popularidad le ayudasen a conseguir trabajo; en su caso como profesora o dando conferencias, en una época en que éstas eran muy populares. Sin duda que, en muchos aspectos, fue una verdadera pionera y precursora de muchas prácticas que hoy en día consideramos como normales.

En ella se unía la acostumbrada soledad del creador con la casi permanente carencia afectiva. Pese a la aparente inocencia que traslucía su enamoradiza 
figura, se notaba en su poesía mucha amargura. Seguramente influía el ser una involuntaria transgresora en lo que en un hombre hubiera sido visto más favora blemente: de muy joven se enamoró perdidamente de un hombre de familia de abolengo, casado además. No sólo era él mucho mayor, sino que, en algo que nunca se le perdonó a ella y sí a él: tuvieron un hijo natural que Storni defendió siempre. Al respecto, en su poema "La loba" comenta:

Yo soy como la loba.

Quebré con el rebaño y me fui a la montaña fatigada del llano.

Yo tengo un hijo fruto del amor, amor sin ley...

Yo soy como la loba, ando sola y me río del rebaño.

El sustento me lo gano y es mio donde quiera que sea, que yo tengo una mano que sabe trabajar y un cerebro que es sano.

El hijo y después yo, y después ... jlo que sea! (Roxlo-Mármol, p. 61).

Hasta el final de su vida, con su poético pero patético suicidio en el mar cuando sabía que tenía un cáncer incurable, Storni jamás pudo aspirar más que a puestos menores. Además, la terrible soledad que sufrió es de alguna manera compartida por casi todas sus colegas escritoras, que no sólo fueron incomprendidas en conjunto, sino que, además, nunca tuvieron el reconocimiento que algunas de ellas hubieran merecido. Un ejemplo de la directa alusión que hace Storni de su permanente soledad, se encuentra en el poema "El divino amor" de Irremediablemente (1919):

Te ando buscando amor que nunca llegas,

Te ando buscando amor que te mezquinas;

Me aguzo por saber si me adivinas, Me doblo por saber si te me entregas

(Roxlo-Mármol, p. 99).

Después de su muerte, ninguna otra poetiza argentina (y para el caso novelista o de cualquier otro género) - salvo muy posteriormente Alejandra Pizarnik (1936-1972) - alcanzará la calidad de su obra y la fama que en vida justiciera mente mereciera. Por lo dicho, se puede afirmar que su caso fue casi 
SZMETAN R. La situación social de las escritoras argentinas...

único, ya que además por lo menos en su trato con sus colegas hombres, era considerada por ellos como una igual y tratada en concordancia a esa especial valoración con que se la honoraba.

\section{Otras escritoras argentinas de principios de siglo}

Como queda dicho, la mayoría de las escritoras argentinas de principios de siglo tuvieron que resignarse a un papel secundario, ya que eran juzgadas en su mayor parte por un reaccionario patriarcado paternalista que muy poco respetaba sus condiciones intelectuales. Con todo, una de las más favorecidas por los lazos de sangre era sin duda la nieta del general Bartolomé Mitre (1821-1906), Margarita Abella Caprile (1901-60), quien dirigiera la sección literaria del prestigioso diario La Nación, propiedad de su familia. En 1938 obtiene el Premio Municipal de Poesía con 50 poesías. Otras escritoras a mencionar son Emilia Bertolé (1901-1949), autora de Espejo en sombra (1927); Herminia C. Brumana (1901-1954), maestra de profesión y quien escribiera Cabezas de mujeres (1923), Mozaico (1929) y el primer trabajo crítico sobre José Hernández (1834-1886) hecho por una mujer: Cartas a las mujeres argentinas: Nuestro hombre (1936). María A. Domínguez (1908-?), por su parte, es recordada por Crepúsculos de oro (1926) y Redención, que recibe el Premio Nacional de Literatura del bienio 1933-35. Por último, se puede citar también a María R. Adler (1901-?), autora de Revelación (1922) y La divina tortura (1927). Para un estudio pormenorizado del tema sigue vigente - pese al paso del tiempo - el monumental trabajo de Helena Percas (1958) ${ }^{6}$.

De todas maneras, cualquier análisis revisionista de la época que se haga - como el reciente de Francine Masiello (1997), por ejemplo - , tendrá que tener en cuenta los factores socio-políticos-económicos aludidos, sin los cuales se caerá en falsos reducionismos y no se entenderá el vacío que produjo en muchas escritoras leyes no escritas, pero de cumplimiento casi inexorable, en contra de sus legítimas aspiraciones. En las siguientes décadas, siguiendo tímidos pero reales avances en el aspecto social y profesional, entre los cuales se destaca el derecho al voto y la mayor participación de la mujer en la vida laboral y profesional, se notará una mayor cantidad de escritoras a mecionar, ya no siendo ya una rareza encontrarlas en ambientes tenidos hasta entonces por feudos masculinos. El avance es real pero está lejos todavía la época en que se pueda analizar su obra haciendo abstracción de su sexo. 
SZMETAN R. La situación social de las escritoras argentinas...

\section{Notas} ejemplo:

1. Sobre lo que he escrito anteriormente sobre el tema social de los escritores, ver, por

Szmetan, Ricardo. La situación del escritor frente a la sociedad en algunas obras de Manuel Gálvez (1916-1935). New York: Peter Lang, 1994.

. La situación del escritor frente a la sociedad en algunos cuentos de Rubén Darío. Revista Iberoamericana, n. 50, p. 415-423, 1989.

Sobre las ruinas de Roberto J. Payró, dentro del contexto de la época." Revista Interamericana de Bibliografia, n. 40, p. 212-217, 1990.

2. En la siguiente nómina, que en ningún quiere ser exaustiva sino más bien indicativa, se veen bastantes nombres de escritoras argentinas que, en muchos casos, todavía siguen vigentes en la escena local. De alguna manera siguen el camino pionero de sus congéneres de principios de siglo: Gloria Alcorta (1915-); María A. Bosco (1917-); Silvina Bullrich (1915-89), Estela Canto (1919-), Sara Gallardo (ca. 1934- ?); Griselda Gambaro (1928-); Carmen Gándara (1900-77); Mária Granata (1921-); Beatriz Guido (1924-); Alicia Jurado (1915-); Norah Lange (1906-72); Luisa M. Levinson (1914-); Pilar de Lusarreta (1914-67); Marta Lynch (1925-85); Olga Orozco (1920-); Elvira Orphee (1930-); Syria Poletti (1921-); Marta Traba (1930-83); María de Villa-reno (1905-); Maria E. Walsh (1930-).

3. Otra de las pioneras instituciones literarias a destacar es la Academia Argentina, que luego de la federalización de la capital es inaugurada en 1876, presidiéndola Juan Carballido. El segundo presidente (1877-79) fue Martín Coronado (1850-1919), acompañado de figuras tales como Martín García Merou (1862-1905), Rafael Obligado (1851-1920), Carlos Vega Belgrano, Ernesto Quesada (1858-1934), Adolfo Lamarque (1852-88) y Eduardo L. Holmberg (1852-1937). Trataron de afianzar lo nacional ante el avance del reinante cosmopolitismo. La Academia reunió unas 4000 voces para la formación de un diccionario de argentinismos, cuyas fichas se perdieron. Con ese antecedente, la Academia Argentina de Letras como se la conoce hoy en día, nació por un decreto presidencial de José F. Uriburu (1868-1932) del 13 de agosto de 1931, contando con 20 miembros en sus comienzos (todos hombres; algunas pocas mujeres serían designadas mucho después), bajo la iniciativa de Gálvez, el historiador y hombre del Régimen Carlos Ibarguren (1877-1956), y Guillermo Rothe (1879-1959), ministro de Justicia e Instrucción Pública. Aparte de ellos, formaban parte como primeros académicos, el crítico Juan P. Echaguie (1877-1950), el poeta Enrique Banchs (1888-1968) y los ensayistas Joaquín Castellanos (1861-1932) y Juan B. Terán (1877-1956). Su Boletín publica en general artículos de sus miembros y nació junto a la Academia en 1933 bajo la dirección de Terán, y se mantuvo inalterable hasta enero de 1952 cuando, por razones políticas, se suspendió su aparición, lo que duró hasta 1956. Hasta la fecha sigue aportando importantes estudios sobre la literatura argentina. Normalmente se le critica lo conservador de su enfoque, pero siendo las academias por naturaleza poco predispuestas a los cambios, no se debería juzgarla con demasiada dureza al respecto. En realidad, quien estudie seriamente la literatura argentina no puede pasarse sin consultarla, ya no fuera que por sus aportes bibliográficos y la información sobre nuevas palabras incorporadas al diccionario de la lengua, una de sus funciones más importantes. La calidad de los trabajos presentados en su boletín es buena, teniendo los colaboradores el espacio necesario para desarrollar con comodidad los temas más diversos. La dirección de la revista cambia a medida que se renuevan las autoridades. También han publicado libros de sus miembros y de otros escritores bastante olvidos con el paso del tiempo. 
4. Lichtblau, en su remarcable - por lo completo - trabajo sobre la novelística argentina del siglo XIX, afirma correctamente lo siguiente, porque si bien siempre ha habido quienes trataran de vivir del usufructo de su pluma, tenían que tener actividades colaterales, principalmente como periodistas: "Only Cambaceres and Ocantos even approached the status of profesionals novelists. 19 th century Argentine society was not ready to receive that type of writer, for it was virtually impossible for an author, however talented he might have been, to sustain himself exclusively on the proceeds of his novels. Owing to this condition, it is safe to assume that much novelistic talent remained undeveloped and even untested; yet, considering all, the number of writers who at least tried their fortune at fiction writing was truly impresive. It was not before the 20 th century in the persons of Wast and Galvez, that the true professional and full-fledged novelists appeared" (p. 204). Además, debe considerarse dentro de la situación personal de cada uno de los escritores citados, ya que en la mayoría de los casos no necesitaban trabajar para vivir, en particular Cambaceres, quien venía de una de las familias más ricas del país. Por su parte, Carlos M. Ocantos (1860-1950) era diplomático de carrera y como tal vivió fuera del país la mayor parte de su vida. En sus comienzos Sur salía trimestralmente, con una corta interrupción entre 1934 y 1935 . Luego, desde entonces hasta fines de 1952 se publicó mensualmente, hasta que, finalmente, de 1953 en adelante aparecía en forma bimestral. Se dejó de publicar a la muerte de su fundadora, aunque hay un intento de seguir sacándola en la actualidad. Aparte de los del grupo de Florida, la revista contaba con la colaboración de conocidos escritores de todo el mundo. La misma mostraba un interés especial en el análisis de las ideas en general y en el aspecto estético de la literatura en particular. Lamentablemente, pese al innegable interés que tuvo en la divulgación de la cultura para un gran círculo de lectores, descuidó el desarrollo de las actividades literarias nacionales, salvo las del pequeño grupo que participaba en ella.

5. Nació Storni en Sala Capriasca (cantón suizo del Ticino) el 22 de mayo de 1892. A los cuatro años se traslada con sus padres a la Argentina. Vive en Santa Fe, Rosario y Buenos Aires, ciudad en la que se suicidó el 25 de octubre de 1938. Publicó siete libros de poemas: La inquietud del rosal (1916), El dulce diario (1918), Irremediablemente (1919), Languidez (1920), Ocre (1925), Mundo de siete pozos (1934) y Mascarilla y trébol (1938), además de una Antologfa poética (1938) que contenía poesías inéditas y un libro de poemas en prosa: Poemas de amor (1926). La biblografía sobre Storni no deja de aumentar con el paso del tiempo. Entre la misma se destacan los siguientes trabajos: 1976.

ANDREOLA, Carlos A. Alfonsina Storni: vida-talento-sociedad. Buenos Aires: Plus Ultra,

ARMANI, Horacio. La renovación poética de Alfonsina Storni. Boletín de la Academia Argentina de Letras v. 290-210, n. 53, p. 431-439, 1988.

BARALIS, Marta. Bibliografía sobre Alfonsina Storni. Boletín del Fondo Nacional de las Artes, n. 8, 1964.

CAPDEVILA, Arturo. Alfonsina: época, dolor y obra de Alfonsina Storni. Buenos Aires: Centurión, 1948.

ESTRELLA GUTIÉRREZ, Fermín. Alfonsina Stomi. Su vida y su obra. Boletín de la Academia Argentina de Letras v. 91-92, n. 24, p. 29-55, 1959.

ETCHENIQUE, Nira. Alfonsina. Buenos Aires: La Mandrágora, 1958. 
FERNÁNDEZ, Javier. A veinticinco años de la muerte de Alfonsina Storni. Cuadernos del Congreso por la Libertad de la Cultura, p. 93-96, 1964.

FERNÁNDEZ MORENO, César. Dos épocas en la poesía de Alfonsina Storni. Revista Hispánica Moderna, n. 24, p. 27-35, 1958. . Situación de Alfonsina Stormi. Santa Fe: Castellvi, 1959.

FORGIONE, José. Alfonsina. Buenos Aires: Librería Argentina, 1943.

KIRKPATRICK, Gwen. The creation of Alfonsina Storni. Ed. Marjorie Agosin. A dream of light and shadow: portraits of latin-american women writers. Albuquerque: University of New Mexico Press, 1995. p. 95-117.

JONES, Sonia. Alfonsina Storni. Boston: Twayne. 1979.

GATELL, Angelina. Delmira Agustini y Alfonsina Stomi: dos destinos trágicos. Cuadernos Hispanoamericanos, n. 58, p. 583-594, 1984.

GÓMEZ-PAZ, Julieta. Leyendo a Alfonsina Storni. Buenos Aires: Losada, 1966.

NALÉ ROXLO, Conrado; MÁRMOL, Mabel. Genio y figura de Alfonsina Stomi. Buenos Aires: EUDEBA, 1964.

NOSOTROS. Alfonsina Storni. Número especial, v. 3, n. 8, 1938.

MORELLO-FROSCH, Marta. Tradición y modernidad en Alfonsina Stomi. Rfo de la Plata n. 46, p. $141-151,1987$. 1940.

OROSCO, María T. Alfonsina Storni. Buenos Aires: Instituto de Literatura Argentina.

SALGADO, María. Alfonsina Stomi in her self-portraits: the woman and the poet. Confluencia. v. 7, n. 2, p. 37-46, 1992.

STORNI, Alejandro. Prólogo. Poesías de Alfonsina Storni. Buenos Aires: EUDEBA, 1961.

PHILLIPS, Rachel. Alfonsina Storni: from poetess to poet. London: Tamesis, 1975.

TITIEV, Janice G. The poetry of dying in Alfonsina Stomi's last book. Hispania v. 68, $\mathrm{n}$. 3, p. $467-473,1985$.

VEIRAVÉ, Alfredo. Feminismo y poesía: Alfonsina Stomi. Capítulo 34: La historia de la literatura argentina. Buenos Aires: Centro Editor de América Latina, 1980. p. 793-816.

6. De la nada profusa bibliografía sobre estas escritoras, se pueden mencionar los trabajos siguientes particulares y otra más general:

ALONSO PIÑEIRO, Armando. Poesía mistica de América: María Raquel Adlér. Buenos Aires: Prestigio, 1957.

BONET, Carmelo M. Margarita Abella Caprile. Buenos Aires: Ediciones Culturales Argentinas, 1962.

RODRIGUEZ TARDITI, José. Herminia C. Brumana, escritora y maestra. Buenos Aires, 1956. 
SZMETAN R. La situación social de las escritoras argentinas...

PERCAS, Helena. La poesía de María Adela Domínguez. Revista Hispánica Modema, n. 21, p. $127-140,1955$.

WASPNIR, Salomón. Perfil y obra de Herminia C. Brumana. Buenos Aires: Perlado, 1957.

BATTICUORE, Graciela. Itinerarios culturales: dos modelos de mujer intelectual en la Argentina del siglo XIX. Revista de Crítica Literaria Latinoamericana v. 22, n. 42-43, p. 163-180, 1996.

BARRANCOS, Dora. Entre la celebración y el escarnio: mujeres contestatarias (18901900). Ed. Lea Fletcher. Mujeres y cultura en la Argentina del siglo XIX. Buenos Aires: Feminaria, 1994.

FLETCHER, Lea. Patriarchy, medicine and women writers in nineteenth-century Argentina Ed. Bruce Clarke; Ed. Wendell Ayock. The body and the text: comparative essays in literature and medicine. Texas Tech University Press, 1990. p. 91-101.

FREDERICK, Bonnie. In their own voice: the women writers of the generación del ' 80 in Argentina. Hispania, v. 74, n. 2, p. 282-289, 1991.

MASIELLO, Francine. Entre civilización y barbarie. Rosario: Beatriz Viterbo, 1997.

. (Ed.) La mujer y el espacio público: el periodismo femenino en la Argentina del siglo XIX. Buenos Aires: Feminaria, 1994.

. Voces de(1) Plata: dinero, lenguaje y oficio literario en la literatura femenina de fin de siglo." Ed. Lea Fletcher. Mujeres y cultura en la Argentina del siglo XIX. Buenos Aires: Feminaria, 1994.

MEAD, Karen. Gendering the obstacles to progress in positivist Argentina. The Hispanic American Historical Review, p. 645-675, 1977.

SEIBEL, Beatriz. Mujer, teatro y sociedad en el siglo XIX en Argentina. Ed. Lea Fletcher. Mujeres y cultura en la Argentina del siglo XIX. Buenos Aires: Feminaria, 1994. p. 291-297. 
SZMETAN R. La situación social de las escritoras argentinas...

\section{RESUMEN}

En este artículo trato la situación socioeconómica de las escritoras argentinas a principios del siglo XX, en especial Alfonsina Storni, en relación con la situación general del escritor argentino. El analisis es sociológico y político, ademas de darse relación a ideas de género y de la teoria feminista.

Palabras-clave: literatura argentina, escritoras argentinas del principio del siglo $\mathrm{XX}$, situación del escritor.

\section{RESUMO}

Neste artigo trato a situação socioeconômica das escritoras argentinas no princípio do século XX, em especial Alfonsina Storni, em relação à situação geral do escritor argentino. A análise é sociológica e política, além de fazer relaçōes com idéias de gênero e da teoria feminista.

Palavras-chave: literatura argentina, escritoras argentinas do princípio do século XX, situação do escritor.

\section{BIBLIOGRAFÍA}

BEAUVOIR, Simone de. The second sex. Trad. de H. M. Parshley. New York: Alfred A. Knopf, 1970.

GALÍNDEZ, Bartolomé, (Ed.) Antología de poetas jóvenes. Buenos Aires: 1902.

GILBERT, Sandra; GUBAR, Susan. The madwoman in the Attic: the woman writer and the ninetenth-century literary imagination. New Haven, London: Yale University Press, 1984.

GONZÁLEZ CASTRO, Augusto. Panoramas de las antologías argentinas. Prol. Alberto Blasi Brambilla. Buenos Aires: Francisco A. Colombo, 1966.

GORRITI, Juana M. La quena: sueños y realidades. Ed. Vicente Quesada. v. 1. Buenos Aires: Imprenta de Mayo, 1865.

. Panoramas de la vida. Ed. Carlos Casvalle. Buenos Aires: Imprenta de Mayo, 1876.

Sueños y realidades. Buenos Aires: Félix Lajouane, 1865.

$\overline{\text { IGÓN }, ~ J . ~ B . ~ A l b u m ~ p o e ́ t i c o ~ p a r a ~ n i n ̃ a s . ~ B u e n o s ~ A i r e s: ~} 1902$. 
SZMETAN R. La situación social de las escritoras argentinas...

LICHTBLAU, Myron I. The Argentine novel in the XIX century. New York: Hispanic Institute in the United States, 1959.

MANSILLA DE GARCÍA, Eduarda. El médico de San Luis. Buenos Aires, 1879. . Lucía. Buenos Aires: Tribuna, 10 mayo al 4 jul. 1860. . Lucía Miranda. Buenos Aires: Imprenta de Juan Alsina, 1882.

MANSO DE NORONHA, Juana. La familia del comendador. Buenos Aires, 1854 . Los misterios del Plata. Buenos Aires: Imprenta de los Mellizos, 1899. . Un compendio de historia de las Provincias Unidas del Río de la Plata. Buenos Aires, 1862.

MARX, Karl. Preface and introduction to a contribution to the critique of political economy. Pekín: Foreign Languages Press, 1976.

MASIELLO, Francinc. Entre civilización y barbarie. Rosario: Beatriz Viterbo, 1997.

MILLET, Kate. Sexual politics. New York: Doubleday, 1970.

MISTRAL, Gabriela. Lectura para mujeres. Méjico: 1924.

MIZRAJE, María G. La pluma secreta. Clarín, 15 mayo 1997.

MONVEL, Maria. Poetisas de América. Santiago de Chile: Nascimiento, 1930.

MORALES, Ernesto; DANIEL, Novillo Quiroga. Antología contemporánea. Buenos Aires: 1917.

WHITE, Hayden. The content of the form: narrative discourse and historical representation. Baltimore: John Hopkins University Press, 1987. 